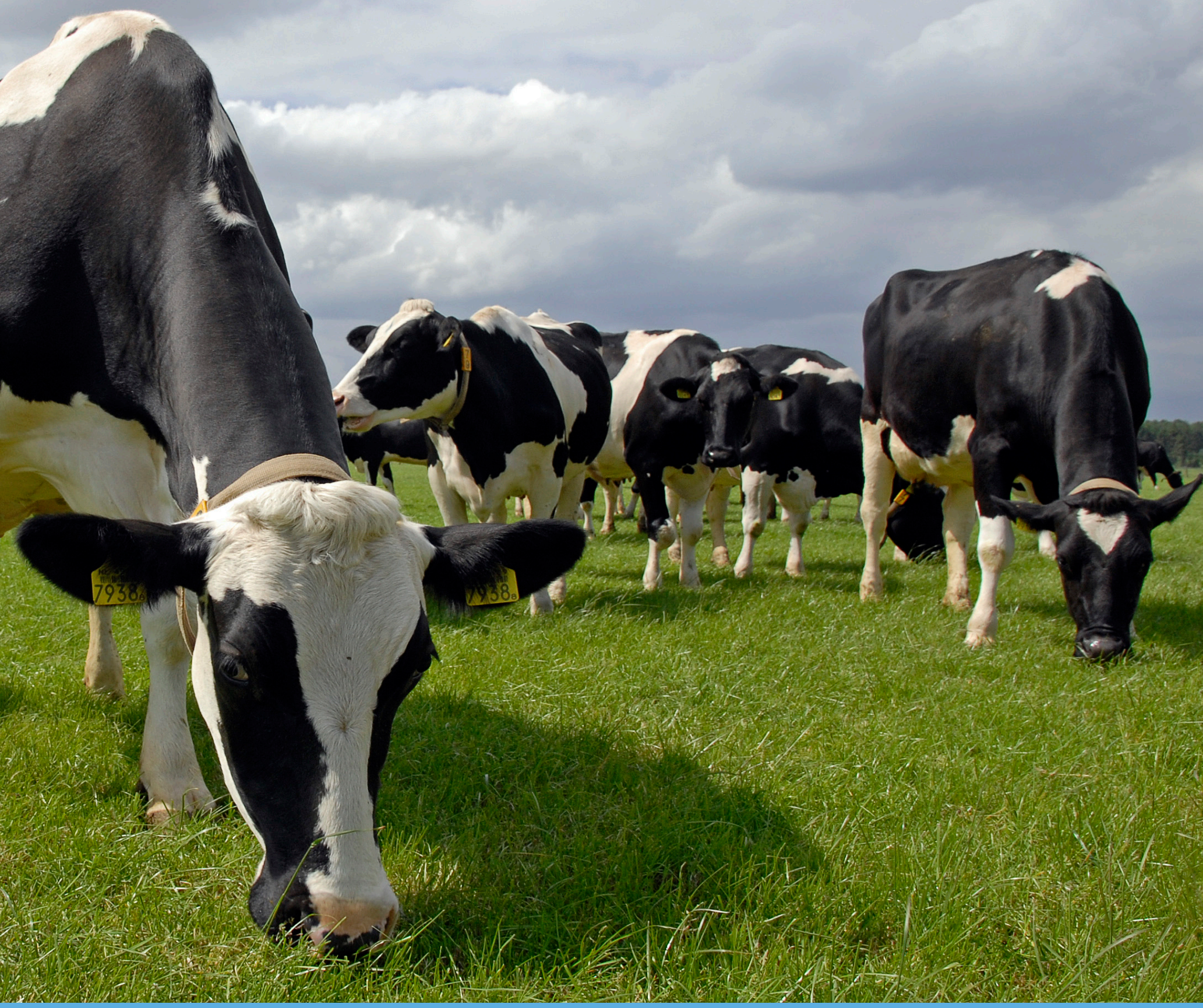

Rassenbericht Grasland 2020 



\section{Rassenbericht Grasland 2020}

Jan Rinze van der Schoot, Henk Schilder

Het Cultuur- en Gebruikswaarde Onderzoek voedergrassen is uitgevoerd door Wageningen Livestock Research in opdracht van en gefinancierd door Plantum.

Wageningen Livestock Research

Wageningen, november 2020

Openbaar

Rapport 1281 
Schoot, J.R. van der, Schilder, H. Rassenbericht Grasland 2020; Wageningen, Wageningen Livestock Research, Rapport 1281.

\section{Samenvatting NL}

Rapportage van proefveldresultaten van het rassenonderzoek aan Engels raaigras in de periode 20122019.

Dit rapport is gratis te downloaden op https://doi.org/10.18174/534161 of op www.wur.nl/livestock-research (onder Wageningen Livestock Research publicaties).

\section{(cc) BY-NC}

Dit werk valt onder een Creative Commons Naamsvermelding-Niet Commercieel 4.0 Internationaallicentie.

(C) Wageningen Livestock Research, onderdeel van Stichting Wageningen Research, 2020 De gebruiker mag het werk kopiëren, verspreiden en doorgeven en afgeleide werken maken. Materiaal van derden waarvan in het werk gebruik is gemaakt en waarop intellectuele eigendomsrechten berusten, mogen niet zonder voorafgaande toestemming van derden gebruikt worden. De gebruiker dient bij het werk de door de maker of de licentiegever aangegeven naam te vermelden, maar niet zodanig dat de indruk gewekt wordt dat zij daarmee instemmen met het werk van de gebruiker of het gebruik van het werk. De gebruiker mag het werk niet voor commerciële doeleinden gebruiken.

Wageningen Livestock Research aanvaardt geen aansprakelijkheid voor eventuele schade voortvloeiend uit het gebruik van de resultaten van dit onderzoek of de toepassing van de adviezen.

Wageningen Livestock Research is NEN-EN-ISO 9001:2015 gecertificeerd.

Op al onze onderzoeksopdrachten zijn de Algemene Voorwaarden van de Animal Sciences Group van toepassing. Deze zijn gedeponeerd bij de Arrondissementsrechtbank Zwolle. 


\section{Inhoud}

Inhoud

1

Inleiding

5

2

$\begin{array}{ll}\text { Resultaten } & \mathbf{7}\end{array}$

2.1 Toelichting op de tabellen $\quad 8$

2.2 ENGELS RAAIGRAS LAAT DOORSCHIETEND 9

2.3 ENGELS RAAIGRAS MIDDENTIJDS DOORSCHIETEND 11 


\section{$1 \quad$ Inleiding}

Dit Rassenbericht Grasland 2020 bevat de nieuwste resultaten van het Cultuur- en Gebruikswaarde Onderzoek (CGO) van Engels raaigras. In het CGO worden rassen van voedergrassen en witte klaver getest op hun landbouwkundige waarde voor de veehouder. Bij goede resultaten komen de rassen op de Aanbevelende Rassenlijst. Voor grasland zijn vooral de eigenschappen standvastigheid, ziekteresistentie (zoals resistentie tegen kroonroest bij Engels raaigras), wintervastheid en drogestofopbrengst belangrijk. De eigenschappen worden beoordeeld op beweidings- en maaiproefvelden, waar de nieuwe rassen samen met de bestaande rassenlijstrassen worden uitgezaaid en onderzocht. 


\section{Resultaten}

Weergegeven zijn de proefveldresultaten van het CGO voor Engels raaigras laat en middentijds doorschietend van de afgelopen jaren. Voor de meeste eigenschappen en de opbrengsten hebben de gegevens betrekking op het gemiddelde van de resultaten verkregen in de periode $2012 \mathrm{t} / \mathrm{m} 2019$. Vermeld zijn de rassenlijstrassen van de Aanbevelende Rassenlijst Veehouderij 2021 en de rassen in onderzoek van de uitzaaijaren 2016 en 2017. De rassen van 2016 zijn reeds beoordeeld voor opname op Rassenlijst 2021.

In dit Rassenbericht Grasland 2020 zijn van Engels raaigras de nieuwe, aanbevolen rassen van Rassenlijst 2021 vermeld met hun waarderingscijfers. De opname en volgorde is gebaseerd op het advies en het persbericht van de Commissie Samenstelling Aanbevelende Rassenlijst (CSAR).

Voor opname is ook inschrijving in het Nederlands Rassenregister en/of EU-verkeerstoelating nodig. De rassen van 2017 worden volgend jaar beoordeeld, omdat het onderzoek nog niet is afgerond. Voor de overige (gras)soorten die in de Aanbevelende Rassenlijst staan vermeld, zijn geen nieuwe gegevens verkregen. Voor meer informatie over grassoorten, graslandmengsels en raseigenschappen wordt verwezen naar de Aanbevelende Rassenlijst Veehouderij 2021, te vinden op https://rassenlijst.info/. Ook de eigenschappen van de rassenlijstrassen van de andere grassoorten en typen (Engels raaigras vroeg doorschietend, gekruist raaigras, Italiaans raaigras, timothee en beemdlangbloem) en van witte klaver staan hierin vermeld. 


\subsection{Toelichting op de tabellen}

Het jaartal achter de rasnaam geeft het eerste jaar van uitzaai en onderzoek aan.

( ) betekent: gegevens zijn gebaseerd op weinig waarnemingen.

- betekent: geen of onvoldoende waarnemingen.

Een hoog cijfer betekent een gunstige waardering van de betrokken eigenschap.

De drogestofopbrengst is per soort of type weergegeven in verhoudingsgetallen. Deze zijn gebaseerd op het gemiddelde van de $\mathrm{A}$ - en $\mathrm{N}$-rassen van de desbetreffende soort of het type van de Aanbevelende Rassenlijst 2019. Naast de gemiddelde totale jaaropbrengst van de maaiproeven en de beweidingsproeven is ook de opbrengst van de eerste en eerste plus tweede snede vermeld. Het opbrengstniveau van de eerste snede geeft informatie over de voorjaarsgroei in relatie tot de doorschietdatum. De gezamenlijk opbrengst van de eerste plus tweede snede geeft informatie over het opbrengstniveau van het veelal kwalitatief hoogwaardige gras in het voorjaar.

$\mathrm{Bij} 100=\ldots$ ton ds/ha is het opbrengstniveau van de rassenproeven vermeld. De opbrengstniveau's van de beweidingsproeven en de maaiproeven zijn niet direct vergelijkbaar door verschillen in beproevingslocaties en management.

De waarderingscijfers en opbrengstgegevens zijn alleen binnen de soort of het type direct vergelijkbaar. Door verschillen in beproevingsperiode, -omvang en -methode kunnen gegevens niet zondermeer gebruikt worden voor een directe onderlinge vergelijking van typen en soorten.

Afkortingen van namen van kwekers of houders/aanvragers kwekersrecht.

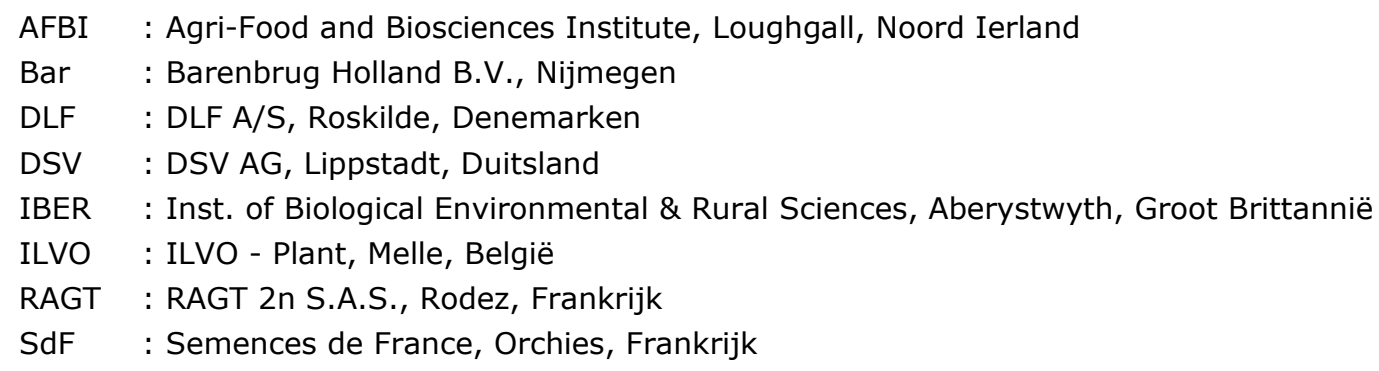

Afkortingen van namen van Nederlandse vertegenwoordigers.

$\begin{array}{ll}\text { Bar } & \text { : Barenbrug Holland B.V., Nijmegen } \\ \text { DLF } & \text { : DLF B.V., Kapelle } \\ \text { DSV } & \text { : DSV zaden Nederland B.V., Gennep } \\ \text { Joo } & \text { : Joordens Zaden B.V., Kessel } \\ \text { Lim } & \text { : Limagrain Nederland B.V., Rilland } \\ \text { VDS } & \text { : Vandinter Semo BV, Scheemda }\end{array}$




\subsection{ENGELS RAAIGRAS LAAT DOORSCHIETEND}

Overzicht van de raseigenschappen

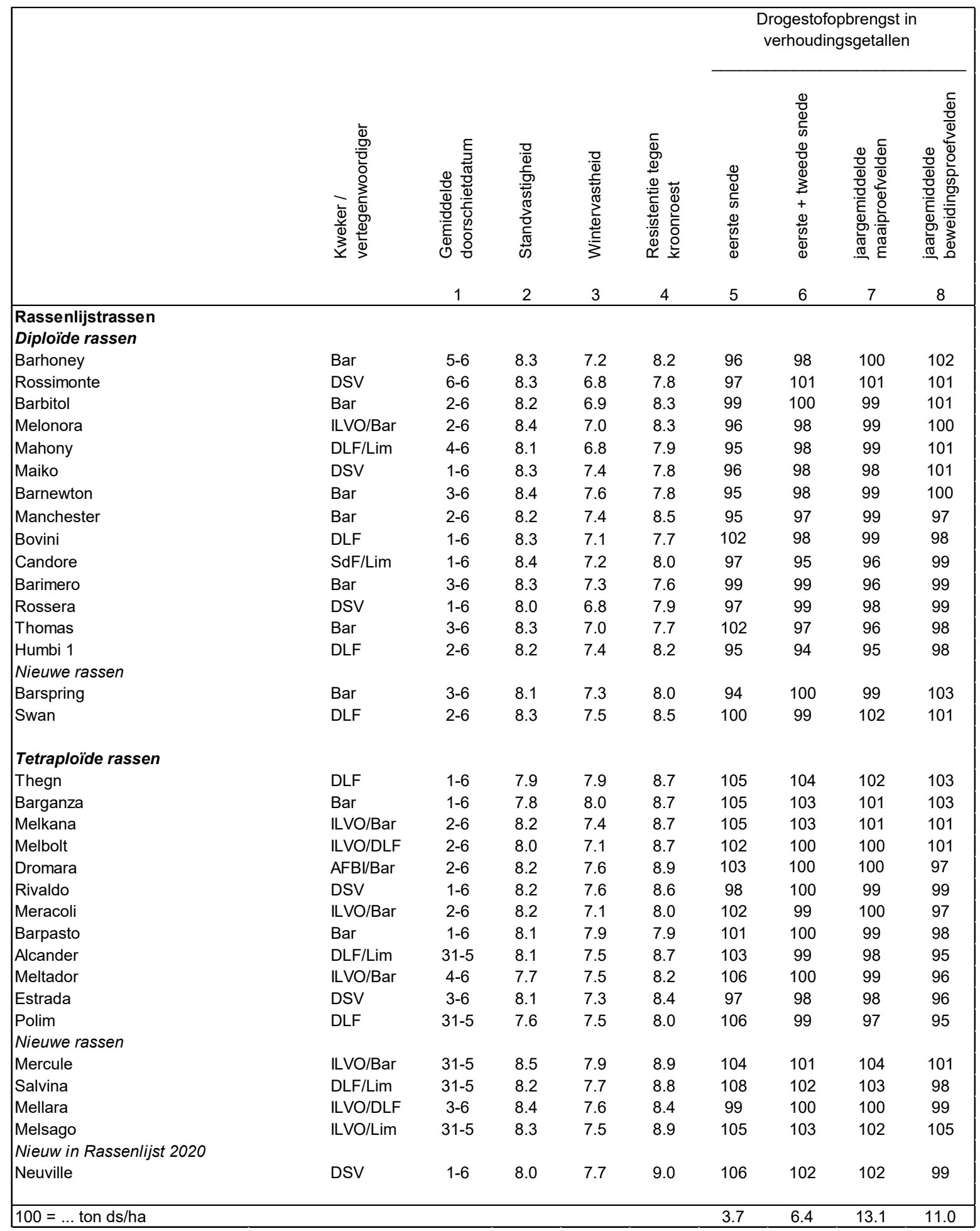




\section{Vervolg ENGELS RAAIGRAS LAAT DOORSCHIETEND}

Overzicht van de raseigenschappen

\begin{tabular}{|c|c|c|c|c|c|c|c|c|c|c|}
\hline & & & & & & & & $\begin{array}{l}\text { gesto } \\
\text { rhoud }\end{array}$ & $\begin{array}{l}\text { brengs } \\
\text { sgetalle }\end{array}$ & \\
\hline & 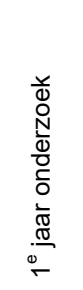 & 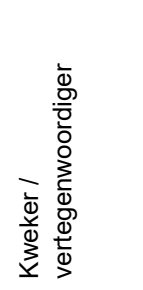 & 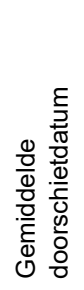 & 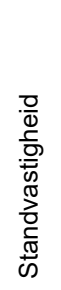 & 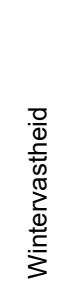 & 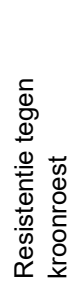 & 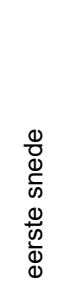 & 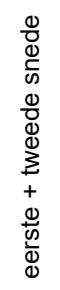 & 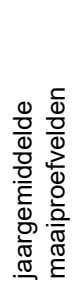 & 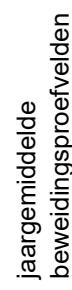 \\
\hline & & & 1 & 2 & 3 & 4 & 5 & 6 & 7 & 8 \\
\hline Rassen in onderzoek & & & & & & & & & & \\
\hline Diploïde rassen & & & & & & & & & & \\
\hline Indul (DSVLp 054218) & 2016 & DSV & $3-6$ & 8.2 & 6.1 & 7.9 & 89 & 91 & 94 & 92 \\
\hline Biro (DSVLp 070721) & 2016 & DSV & $29-5$ & 8.3 & 7.5 & 8.2 & 96 & 95 & 94 & 92 \\
\hline Barkuper (16LPD 148) & 2016 & Bar & $31-5$ & 8.1 & 7.6 & 8.2 & 104 & 99 & 97 & 100 \\
\hline RGAH1019 & 2016 & RAGT/Joo & $2-6$ & 8.1 & 7.6 & 8.6 & 96 & 97 & 98 & 98 \\
\hline Quapau (DLF LFD-023) & 2016 & DLF & $31-5$ & 8.2 & 5.7 & 8.1 & 98 & 96 & 98 & 99 \\
\hline 17LPD 137 & 2017 & Bar & $30-5$ & 8.2 & (7.7) & 9.0 & 97 & 101 & 97 & 100 \\
\hline Medaillion (DSVLp 060526) & 2017 & DSV & $5-6$ & 8.5 & $(7.5)$ & 8.6 & 89 & 94 & 95 & 91 \\
\hline Tapas (DSVLp 070710) & 2017 & DSV & $1-6$ & 8.3 & (7.5) & 8.5 & 89 & 93 & 90 & 95 \\
\hline DT 250 & 2017 & SdF/VDS & $2-6$ & 8.2 & $(6.0)$ & 8.5 & 85 & 93 & 94 & 97 \\
\hline Timuco (DLF LFD-4024) & 2017 & DLF & $1-6$ & 7.9 & (4.0) & 8.0 & 104 & 102 & 99 & 102 \\
\hline Tetraplö̈de rassen & & & & & & & & & & \\
\hline Gasparo (DSVLp 084481) & 2016 & DSV & $29-5$ & 7.9 & 7.7 & 8.5 & 99 & 99 & 98 & 98 \\
\hline 16LPT 215 & 2016 & Bar & $30-5$ & 7.9 & 7.8 & 8.9 & 108 & 101 & 101 & 94 \\
\hline Bargerio (16LPT 221) & 2016 & Bar & $31-5$ & 7.9 & 7.8 & 8.8 & 104 & 100 & 99 & 98 \\
\hline Lassik (DLF LFT-018) & 2016 & DLF & $25-5$ & 6.9 & 7.8 & 8.6 & 109 & 99 & 98 & 92 \\
\hline Cirstea (LMG LFT-092) & 2016 & DLF/Lim & $30-5$ & 8.0 & 7.8 & 8.8 & 110 & 104 & 102 & 99 \\
\hline 17LPT 241 & 2017 & Bar & $1-6$ & 7.8 & $(7.8)$ & 8.2 & 109 & 101 & 100 & 101 \\
\hline Beau (DSVLp 090679) & 2017 & DSV & $3-6$ & 8.3 & (7.8) & 9.0 & 104 & 100 & 102 & 99 \\
\hline Holom (DSVLp 711590) & 2017 & DSV & $29-5$ & 8.1 & $(8.0)$ & 8.4 & 110 & 98 & 100 & 99 \\
\hline Carreo ( $\mathrm{T} \mid 42)$ & 2017 & SdF/Lim & $29-5$ & 8.1 & (7.8) & 8.4 & 106 & 97 & 100 & 94 \\
\hline DLF LFT-4565 & 2017 & DLF & $29-5$ & 8.0 & $(8.0)$ & 9.1 & 113 & 101 & 104 & 97 \\
\hline Boomerang (LMG LFT-4913) & 2017 & DLF/Lim & $1-6$ & 8.0 & $(8.0)$ & 8.9 & 102 & 93 & 94 & 92 \\
\hline ILVO176247 & 2017 & ILVO/DLF & $4-6$ & 8.2 & (7.8) & 7.8 & 90 & 96 & 100 & 96 \\
\hline |LVO176256 & 2017 & ILVO/Lim & $2-6$ & 8.2 & (7.4) & 8.6 & 99 & 95 & 99 & 101 \\
\hline TRAS1102 & 2017 & RAGT/Joo & $2-6$ & 8.1 & (6.9) & 9.0 & 104 & 99 & 100 & 100 \\
\hline $100=\ldots$ ton $d s / h a$ & & & & & & & 3.7 & 6.4 & 13.1 & 11.0 \\
\hline
\end{tabular}




\subsection{ENGELS RAAIGRAS MIDDENTIJDS DOORSCHIETEND}

Overzicht van de raseigenschappen

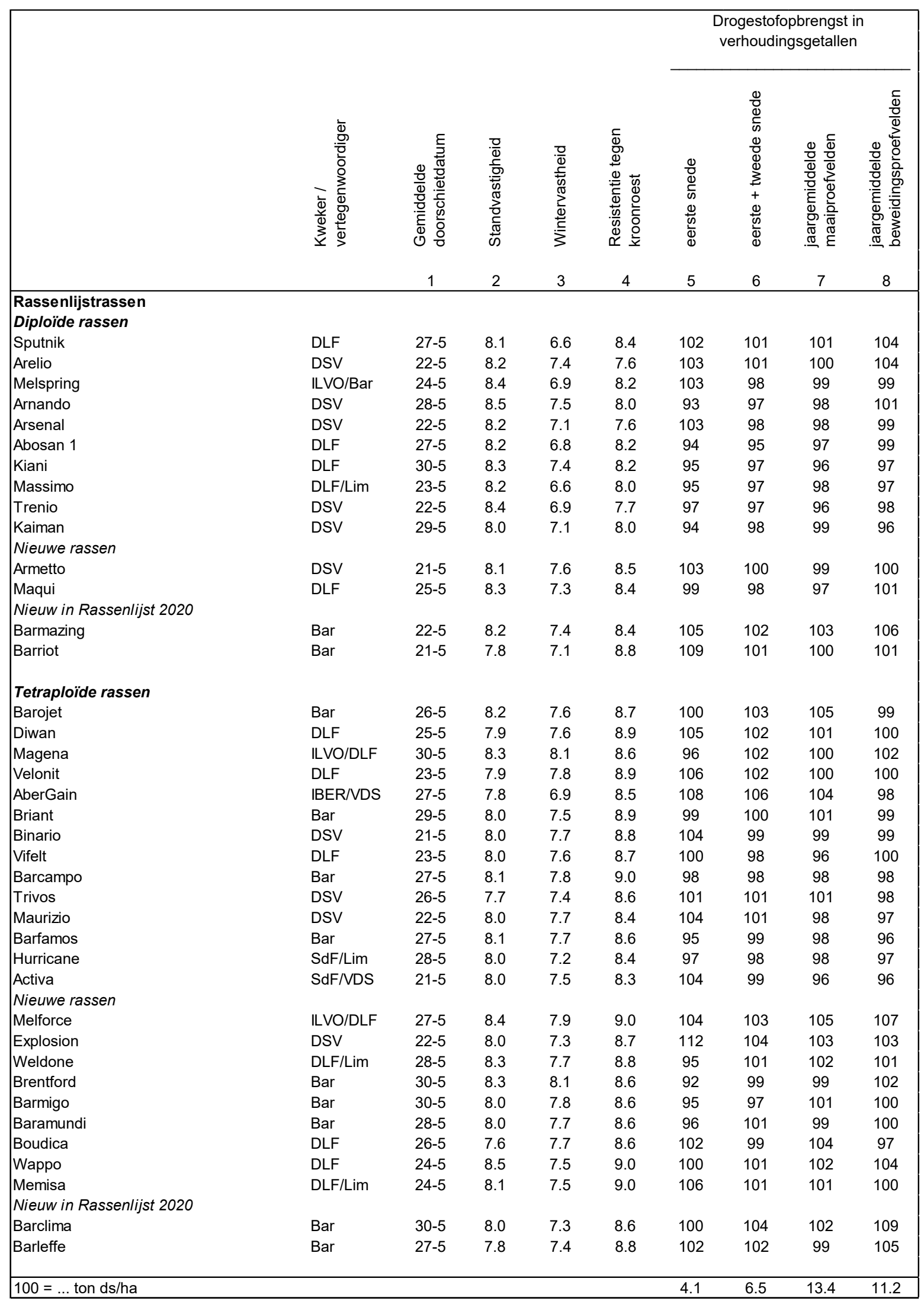


Overzicht van de raseigenschappen

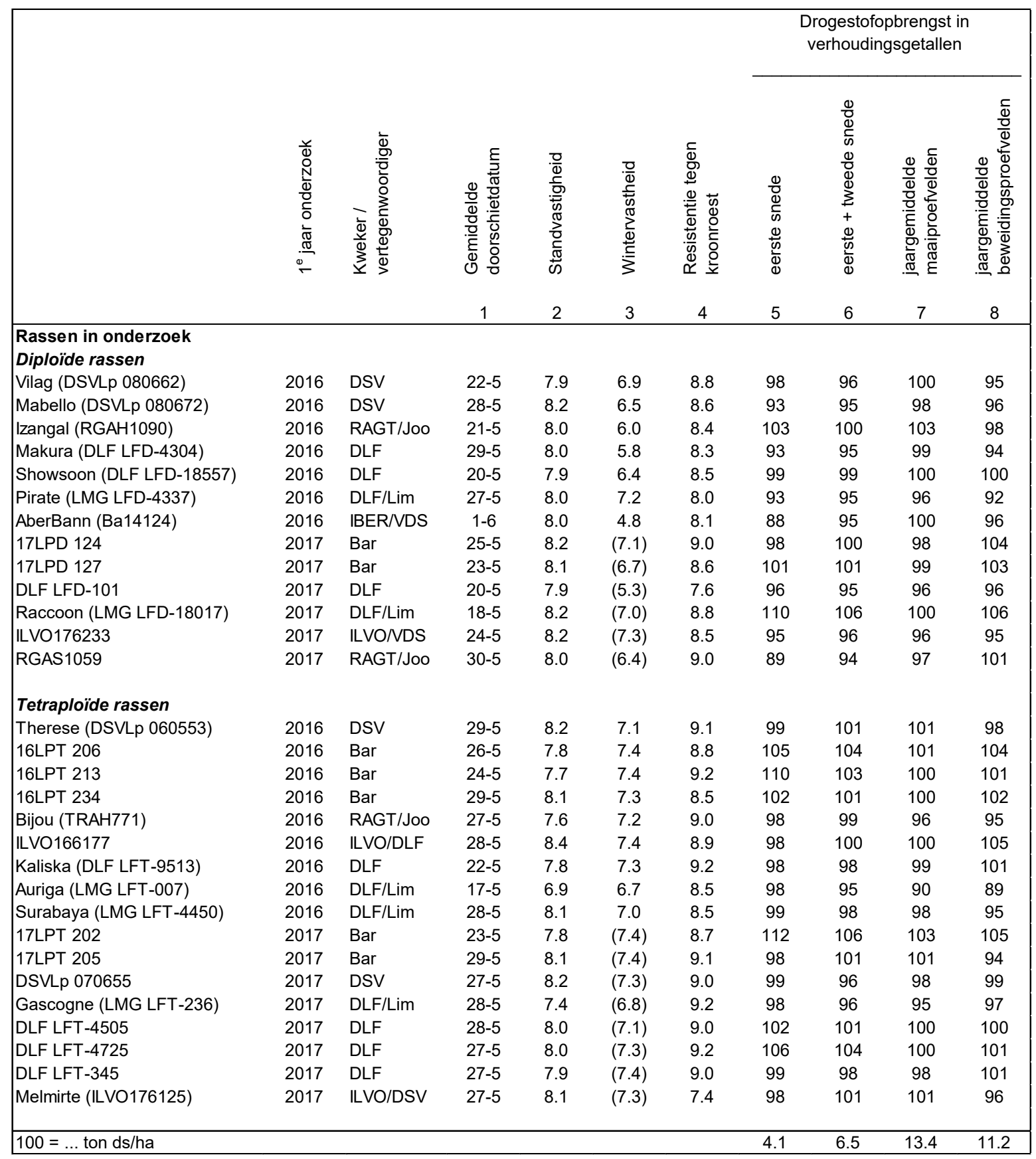





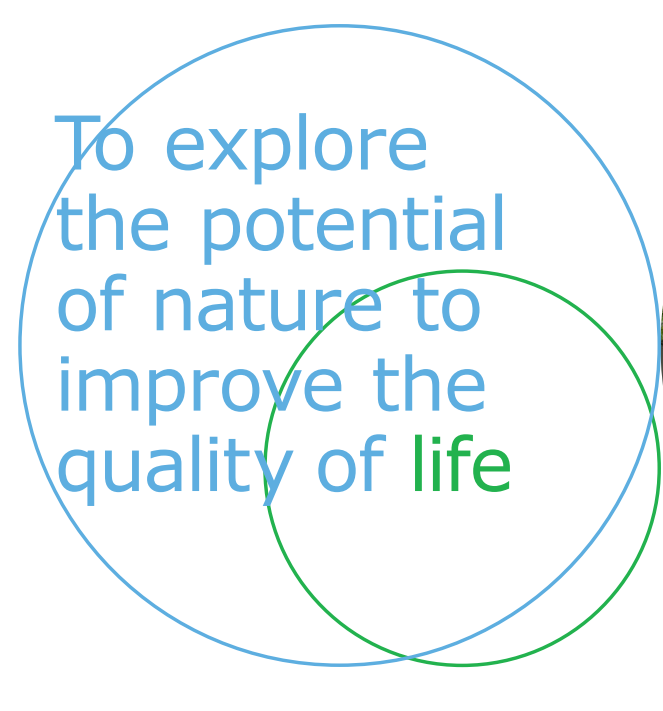

Wageningen Livestock Research Postbus 338

6700 AH Wageningen

T 0317483953

E info.livestockresearch@wur.nl www.wur.nl/livestock-research

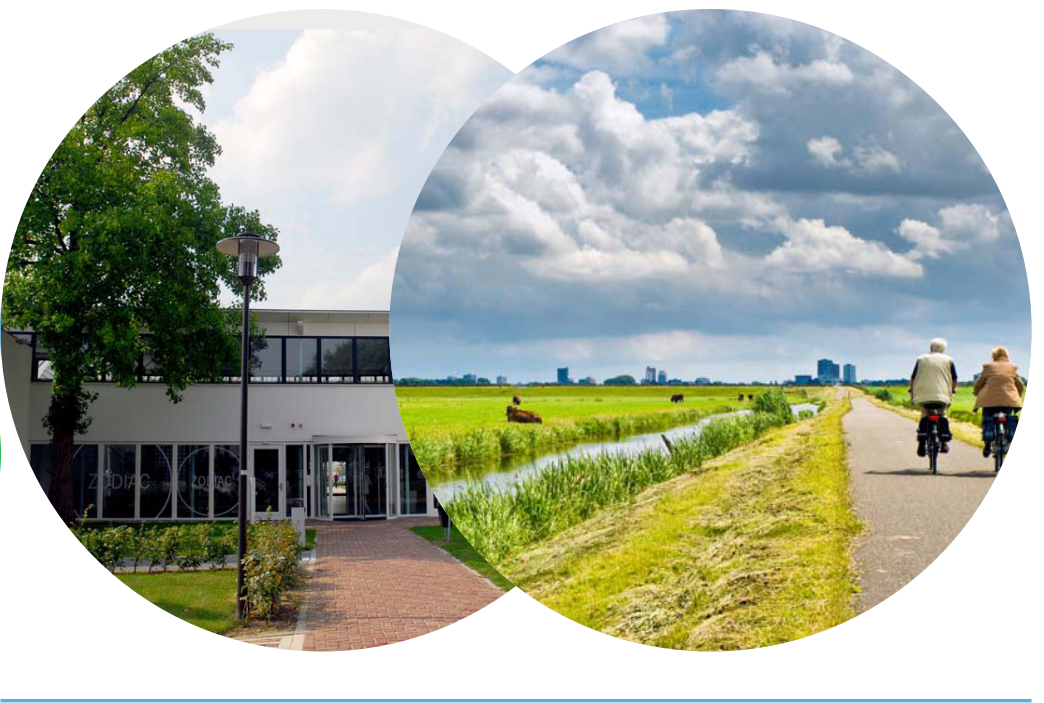

Wageningen Livestock Research ontwikkelt kennis voor een zorgvuldige en renderende veehouderij, vertaalt deze naar praktijkgerichte oplossingen en innovaties, en zorgt voor doorstroming van deze kennis. Onze wetenschappelijke kennis op het gebied van veehouderijsystemen en van voeding, genetica, welzijn en milieu-impact van landbouwhuisdieren integreren we, samen met onze klanten, tot veehouderijconcepten voor de 21 e eeuw.

De missie van Wageningen University \& Research is 'To explore the potential of nature to improve the quality of life'. Binnen Wageningen UR bundelen 9 gespecialiseerde onderzoeksinstituten van stichting DLO en Wageningen University hun krachten om bij te dragen aan de oplossing van belangrijke vragen in het domein van gezonde voeding en leefomgeving. Met ongeveer 30 vestigingen, 6.000 medewerkers en 10.000 studenten behoort Wageningen UR wereldwijd tot de aansprekende kennisinstellingen binnen haar domein. De integrale benadering van de vraagstukken en de samenwerking tussen verschillende disciplines vormen het hart van de unieke Wageningen aanpak. 